\title{
The Anti-Vascular Endothelial Growth Factor Receptor-1 Monoclonal Antibody D16F7 Inhibits Glioma Growth and Angiogenesis In Vivo[
}

\author{
Maria Grazia Atzori, ${ }^{1}$ Lucio Tentori, ${ }^{1}$ Federica Ruffini, Claudia Ceci, Elena Bonanno, \\ Manuel Scimeca, Pedro Miguel Lacal, ${ }^{2}$ and Grazia Graziani ${ }^{2}$ \\ Departments of Systems Medicine (M.G.A., L.T., C.C., G.G.) and Experimental Medicine and Surgery (E.B., M.S.), University of \\ Rome Tor Vergata, Rome, Italy; and Laboratory of Molecular Oncology, "Istituto Dermopatico dell'Immacolata"-Istituto di \\ Ricovero e Cura a Carattere Scientifico, Rome, Italy (F.R., P.M.L.)
}

Received August 4, 2017; accepted October 10, 2017

\section{ABSTRACT}

The vascular endothelial growth factor (VEGF) receptor-1 (VEGFR-1) is a tyrosine kinase receptor that does not play a relevant role in physiologic angiogenesis in adults, whereas it is important in tumor angiogenesis. In high-grade glioma VEGFR-1 expression by tumor endothelium and neoplastic cells contributes to the aggressive phenotype. We recently generated an anti-VEGFR-1 monoclonal antibody (D16F7 mAb) characterized by a novel mechanism of action, since it hampers receptor activation without interfering with ligand binding. The mAb is able to inhibit chemotaxis and extracellular matrix invasion of glioma cells in vitro stimulated by VEGF-A and by the VEGFR-1-selective ligand placental growth factor (PIGF). In this study, we have investigated the influence of D16F7 on glioma growth and angiogenesis in vivo using C6 glioma cells transfected with the human VEGFR-1.
D16F7 was able to inhibit receptor activation and migration and extracellular matrix invasion of $\mathrm{C} 6$ cells overexpressing the receptor in response to PIGF and VEGF-A. In nude mice, treatment with 10 and $20 \mathrm{mg} / \mathrm{kg} \mathrm{D} 16 \mathrm{~F} 7$ as a single agent was well tolerated and significantly inhibited glioma growth $(P<0.001)$. Strikingly, in an intracranial orthotopic model, mice dosed with $20 \mathrm{mg} / \mathrm{kg}$ D16F7 demonstrated a 65\% increase in median survival time compared with vehicletreated controls $(P<0.001)$ with a high percentage of longterm survivors $(46 \%)$. These effects were associated with glioma cell apoptosis and decreased tumor-associated vessel formation. Overall, these results highlight the therapeutic potential of D16F7 in glioma treatment, deserving further investigation after a humanization process as single agent or in combination therapies.

\section{Introduction}

Gliomas are the most common primary tumors of the central nervous system, and glioblastoma (GBM) (grade IV according to the World Health Organization grading system) is the most aggressive glial tumor with an average overall survival time of 12-18 months (Stupp et al., 2005). Standard treatment consists of surgical resection followed by concurrent radiotherapy with the methylating agent temozolomide and subsequent adjuvant therapy with temozolomide. Unfortunately, despite the aggressive multimodality treatment, GBM uniformly recurs and the efficacy of the actual salvage therapies remains modest.

This work was supported by the Italian Association for Cancer Research [Investigator Grant IG 2013 N. 14042 to G.G.] and in part by the Italian Ministry of Health [RC2017 project N. 2630202 to P.M.L.]. No potential conflicts of interest relevant to this article were reported.

${ }^{1}$ M.G.A. and L.T. contributed equally to this work as first authors.

${ }^{2}$ P.M.L. and G.G. contributed equally to this work as last authors.

https://doi.org/10.1124/jpet.117.244434.

S This article has supplemental material available at jpet.aspetjournals.org.
Invasion of the surrounding brain parenchyma, angiogenesis, and abnormal vascular permeability are all hallmarks of glioma progression. Indeed, one of the most frequently used salvage treatments is the anti-vascular endothelial growth factor (VEGF)-A monoclonal antibody (mAb) bevacizumab. However, in the recurrent setting of GBM bevacizumab did not improve overall survival, and no agents have been demonstrated to significantly affect survival after bevacizumab failure (reviewed in Diaz et al., 2017; Hundsberger et al., 2017; Tipping et al., 2017).

Intrinsic or acquired resistance mechanisms toward anti-VEGF-A therapies include increased expression/activation of VEGF-A tyrosine kinase transmembrane receptors (in tumor and tumor microenvironment cells) and/or upregulation of different angiogenic factors including the placental growth factor (PlGF) (Hundsberger et al., 2017). Although VEGF-A binds to both VEGF receptor (VEGFR)-1 (Flt-1) and VEGFR-2 (KDR, Flk-1), PlGF interacts exclusively with VEGFR-1. VEGF-A is known to favor angiogenesis by activating VEGFRs expressed on tumor endothelium, but it also

ABBREVIATIONS: BSA, bovine serum albumin; BW, body weight; CTR, vehicle-treated control; ECM, extracellular matrix; DMEM, Dulbecco's modified Eagle's medium; GBM, glioblastoma; mAb, monoclonal antibody; PBS, phosphate-buffered saline; PIGF, placental growth factor; RT$\mathrm{PCR}$, reverse-transcription polymerase chain reaction; VEGF, vascular endothelial growth factor; VEGFR, vascular endothelial growth factor receptor. 
directly interacts with the receptors expressed on cancer cells, contributing to disease progression. In regard to PlGF, this growth factor seems to have an important disease-associated role because its expression is upregulated in a number of pathologic conditions including cancer (Ferrara et al., 2003; Fischer et al., 2008; Kim et al., 2012; Dewerchin and Carmeliet, 2014). PlGF is secreted by tumor, endothelial, and other cells of the tumor stroma including inflammatory cells.

It is generally agreed that VEGFR-2 is the major receptor mediating the mitogenic, angiogenic, and permeabilityenhancing effects of VEGF-A, and therefore it has received much attention for therapeutic inhibition of angiogenesis. However, therapies that target VEGF-A or VEGFR-2 give rise to systemic toxicity due to the inhibition of physiologic angiogenesis, resulting in, for example, bleeding, hypertension, and delayed wound healing (Higa and Abraham, 2009). On the other hand, VEGFR-1-mediated signaling has a prevalent role in pathologic angiogenesis (Luttun et al., 2002; Shibuya, 2006; Dewerchin and Carmeliet, 2014). VEGFR-1 is expressed in endothelial cells during vessel formation, in macrophages, in myoepithelial cells, and in a variety of human cancers where it stimulates cell migration and survival, inhibits apoptosis, induces chemoresistance, and predicts poor prognosis and recurrence (Wu et al., 2006; Roskoski, 2008; Schwartz et al., 2010; Takahashi, 2011). Moreover, VEGFR-1 is involved in the mobilization of bone marrow-derived cells that generate tumor-associated macrophages, which foster tumor growth and angiogenesis (Li et al., 2011; Qian et al., 2015; Graziani et al., 2016). Besides the transmembrane receptor, a soluble form of VEGFR-1 is released in the extracellular matrix (ECM), where it may sequester VEGF-A, avoiding its interaction with the membrane receptors (Cao, 2009). In high-grade gliomas the coexpression of VEGF-A and its receptors in a consistent percentage of patient-derived tumor cells suggested the presence of an autocrine loop that may favor tumor progression (Steiner et al., 2004). Moreover, we have recently demonstrated that stimulation by PlGF of VEGFR-1 can itself transmit signals that promote GBM cell invasiveness (Atzori et al., 2017).

In this context, we hypothesized that molecules selectively targeting VEGFR-1 may inhibit tumor vascularization and invasiveness while producing less toxic effects than agents directed against VEGF-A or VEGFR-2. Therefore, we generated an anti-VEGFR-1 mAb (D16F7) that, while not affecting the binding of VEGF-A and PlGF to the receptor, reduces its homodimerization and activation by both ligands. This property allows the mAb to preserve the soluble VEGFR-1 ability of acting as a decoy receptor. The mAb exerted inhibitory effects on migration and/or ECM invasion by tumor cells (melanoma, GBM) and tumor microenvironment cells (endothelial and myelomonocytic cells) in response to VEGFR-1 ligands in vitro and on pathologic angiogenesis in vivo (Graziani et al., 2016; Atzori et al., 2017).

Herein we analyze the in vivo therapeutic potential of D16F7 mAb against glioma using rat C6 cells transduced to overexpress the human VEGFR-1. The results of this study indicate that in nude mice D16F7 is well tolerated, inhibits glioma growth and tumor-associated vessel formation, and increases median survival time with a high percentage of longterm survivors.

\section{Materials and Methods}

Cell Lines, Culture Conditions, and Transfection. The rat glioma cell line C6 was obtained from American Type Culture Collection (Manassas, VA). Cells were maintained in Dulbecco's modified Eagle's medium (DMEM) (Sigma-Aldrich, St. Louis, MO) supplemented with $10 \%$ fetal bovine serum (Sigma-Aldrich), $2 \mathrm{mM}$ L-glutamine, $100 \mathrm{U} / \mathrm{ml}$ penicillin, and $100 \mu \mathrm{g} / \mathrm{ml}$ streptomycin sulfate at $37^{\circ} \mathrm{C}$ in a $5 \% \mathrm{CO}_{2}$ humidified atmosphere.

Cell clones were obtained by limiting dilution from $\mathrm{C} 6$ cells, and one clone was transfected with pBLAS49.2 or pBLAS49.2/VEGFR-1 plasmids. The pBLAS49.2/VEGFR-1 construct was obtained by cloning of VEGFR-1 cDNA from pcDNA3/VEGFR-1 plasmid (a gift from Dr. K. Ballmer-Hofer, Paul Scherrer Institute, Zurich, Switzerland) into pBLAS49.2 vector (InvivoGen, San Diego, CA). Transfection was performed using Lipofectamine 2000 (Invitrogen, Camarillo, CA), as described by the manufacturer, and transfected cells were selected in blasticidine (Invitrogen)-containing culture medium. Antibioticresistant clones were isolated by ring cloning, and transfected clones were maintained in the presence of $5 \mu \mathrm{g} / \mathrm{ml}$ blasticidine.

Analysis of VEGFR-1 Transcript. Detection of VEGFR-1 transcript in transfected clones was evaluated by reverse-transcription polymerase chain reaction (RT-PCR) analysis and cDNA preparation followed by PCR amplification, which were performed as previously described (Tentori et al., 2005), using an annealing temperature of $58^{\circ} \mathrm{C}$ and the following primers: human VEGFR-1: forward primer, $5^{\prime}$ CTCCTGAGTACTCTACTCCT-3'; reverse primer, 5'-GAGTACAGGACCACCGAGTT-3' [640-base pair (bp) fragment]; glyceraldehyde-3-phosphate dehydrogenase: forward primer, 5'-TCCCATCACCATCTTCCA-3'; reverse primer, 5'-CATCACGCCACAGTTTCC-3'. The glyceraldehyde-3phosphate dehydrogenase primers recognize both the human and murine gene (380-bp fragment in humans and 379-bp fragment in rats).

Western Blot Analysis. Proteins were run in 10\% SDSpolyacrylamide gels and transferred to supported nitrocellulose membranes by standard techniques. Immunodetection was performed using the following antibodies: mouse monoclonal anti-VEGFR-1 (1:500; clone D2; Santa Cruz Biotechnology, Santa Cruz, CA); rabbit polyclonal anti-phosphorylated VEGFR-1 at tyrosine 1213 (1:500; R\&D Systems, Abingdon, UK); rabbit polyclonal anti-Erk1/2 (1:1000; GeneTex, Irvine, CA); rabbit polyclonal anti-phospho-Erk1/2 (1:1000; Thr/Tyr185/187; Invitrogen); or rabbit polyclonal anti- $\beta$-actin (1:10,000; Sigma-Aldrich) primary antibodies. The anti-VEGFR-1 antibodies recognize only the human protein, whereas the anti-Erk1/2 antibodies have wide species reactivity, including the human and rat proteins. Anti-mouse or antirabbit Ig/horseradish peroxidase secondary antibodies and electrochemiluminescence Western blotting detection reagents from GE Healthcare (Milan, Italy) were used to identify the proteins of interest.

For the analysis of VEGFR- 1 and Erk1/2 phosphorylation, cells $(1 \times$ $10^{6} /$ well) were seeded in six-well plates, allowed to growth overnight in complete medium, starved for 2 hours in serum-free medium [DMEM containing $0.1 \%$ fatty acid-free bovine serum albumin (BSA; Roche, Mannheim, Germany) and $1 \mu \mathrm{g} / \mathrm{ml}$ heparin] and preincubated for 30 minutes at room temperature with the indicated concentrations of D16F7 mAb before stimulation for 10 minutes at $37^{\circ} \mathrm{C}$ with VEGF-A or PlGF (100 ng/ml). Cells were then washed twice with phosphatebuffered saline (PBS) containing protease and phosphatase inhibitors (Thermo Fisher Scientific, Waltham, MA), directly lysed by SDS electrophoresis sample buffer and analyzed by Western blotting.

Chemotaxis Assay and Spheroid Invasion Assay. In vitro migration assay was performed using Boyden chambers equipped with $8 \mu \mathrm{m}$ pore diameter polycarbonate filters (Nuclepore, Whatman Incorporated, Clifton, $\mathrm{NJ}$ ) coated with $5 \mu \mathrm{g} / \mathrm{ml}$ gelatin (Sigma-Aldrich), as previously described (Lacal et al., 2008). Untreated cells or cells treated with the indicated amounts of $\mathrm{D} 16 \mathrm{~F} 7 \mathrm{mAb}$ or of an isotype-matched control (IgG1; R\&D Systems) were incubated in a rotating wheel for 30 minutes at room temperature. Cells $\left(2 \times 10^{5} /\right.$ chamber $)$ were then loaded into the top compartment of Boyden chambers and migration 
assay, toward serum-free medium (containing $0.1 \%$ BSA and $1 \mu \mathrm{g} / \mathrm{ml}$ heparin) or stimuli (50 ng/ml VEGF-A or PlGF) present in the bottom compartment, was performed in the absence or in the presence of D16F7 $\mathrm{mAb}$ for the time specified in figure legends. Migrated cells, attached to the lower side of the filters, were stained with crystal violet and counted in triplicate samples for a total of 12 high-power ( $200 \times$ magnification) microscopic fields.

For spheroid invasion assay, tumor cells $(25,000-30,000$ cells $/ \mathrm{ml})$ were suspended in DMEM, containing 10\% fetal bovine serum, supplemented with methylcellulose $(0.24 \%$ final concentration; Sigma-Aldrich), seeded in 96-well round-bottom cell culture plates (100 $\mu \mathrm{l} /$ well; Corning Costar Ultra-Low Attachment Multi-Well; Sigma-Aldrich) and centrifuged at $3000 \mathrm{~g}$ for 90 minutes (Eskilsson et al., 2016). Plates were then incubated for 24 hours under standard culture conditions $\left(5 \% \mathrm{CO}_{2}\right.$, at $\left.37^{\circ} \mathrm{C}\right)$ to allow spheroid formation. Spheroids were collected, embedded individually in $100 \mu \mathrm{l}$ of $1 \mathrm{mg} / \mathrm{ml}$ collagen I solution (rat tail; Trevigen, Gaithersburg, MD) in $0.1 \%$ BSA/DMEM, with or without PlGF or VEGF-A $(50 \mathrm{ng} / \mathrm{ml})$ and $/$ or $10 \mu \mathrm{g} / \mathrm{ml} \mathrm{D} 16 \mathrm{~F} 7 \mathrm{mAb}$, and plated in each well of a 96 -well flat-bottom plate, previously coated with $50 \mu \mathrm{l}$ of collagen I. Five to eight replicates were set up for each experimental group. Collagen I dilution and neutralization were performed according to the manufacturer instructions. After collagen I solidification at $37^{\circ} \mathrm{C}, 100 \mu \mathrm{l}$ of invasion medium, with or without PlGF or VEGF-A (50 ng/ml), were added and plates incubated overnight at $37^{\circ} \mathrm{C}$ for up to 72 hours. Spheroids were visualized and photographed using a Nikon (Melville, NY) Eclipse TS100 Microscope in conjunction with a Nikon DS-Fi1 highresolution camera. Measurements were performed using Adobe (New York, NY) Photoshop CS6 software. Relative invasion area was defined as the area of spheroids (in square millimeters) at each time point minus the area on day 0 .

D16F7 Binding to VEGFR-1. Quantification of D16F7 binding to VEGFR-1 was performed on 96-well Nuncimmuno Plates Maxisorp (Nalge Nunc International, Roskilde, Denmark) coated with $3 \mu \mathrm{g} / \mathrm{ml}$ human or mouse soluble VEGFR-1 (ReliaTech, Braunschweig, Germany), which corresponds to the receptor extra-cellular domain, in PBS. After blocking of the plates with $2 \% \mathrm{BSA}(\mathrm{w} / \mathrm{v})$ in PBS (hereafter referred to as blocking buffer), $50 \mu \mathrm{l}$ of the indicated concentrations of D16F7 or mouse IgG1 control (R\&D Systems) in blocking buffer were added to selected wells and incubated overnight at $4^{\circ} \mathrm{C}$. Detection of the amount of bound mAb was performed with a goat anti-mouse IgG alkaline phosphatase conjugate antibody (1:500 in blocking buffer; Roche). After alkaline phosphatase reaction, optical density at $405 \mathrm{~nm}$ was measured in a Model 3550-UV Microplate Reader (Bio-Rad, Hercules, CA). The specificity of D16F7 mAb binding to VEGFR-1 was demonstrated by adding the same concentration of $\mathrm{mAb}$ to wells coated with VEGFR-2/Fc chimera (ReliaTech), and background was determined in blocking buffer-coated wells.

In Vivo Studies. To analyze the effect of $\mathrm{D} 16 \mathrm{~F} 7 \mathrm{mAb}$ on in vivo tumor growth, C6-MF1 cells $\left(5 \times 10^{6}\right)$ were initially injected intramuscularly in the left hind limb of 5-week-old male CD1 nude mice (weight, 24-26 g; Charles River, Calco, Italy). When tumor mass was palpable (i.e., 6 days after the injection of tumor cells), animals were randomized into two subgroups and treated intraperitoneally with either $20 \mathrm{mg} / \mathrm{kg}$ D16F7 or the equivalent volume of vehicle (PBS) alone (CTR) on alternate days for up to 2 weeks. Glioma growth was monitored every other day by measuring the tumor mass three times a week in two dimensions by a caliper. Volumes were calculated according to the following formula:

$$
\text { Tumor volume }\left(\mathrm{mm}^{3}\right)=\left[\text { length }(\mathrm{mm}) \times \operatorname{width}^{2}\left(\mathrm{~mm}^{2}\right)\right] / 2
$$

Antitumor efficacy of treatments was assessed by the following end points:

1. The percentage of tumor volume inhibition (TVI\%) in treated versus control mice, calculated as:

$\mathrm{TVI} \%=100-[($ mean $\mathrm{TV}$ treated $/$ mean $\mathrm{TV}$ control $) \times 100]$
2. The tumor growth doubling time, calculated as the time required for tumor volume to increase 2 -fold over initial volume at indicated times, using the following formula:

$$
\mathrm{t}_{\mathrm{d}}=\mathrm{t}_{1}+\left(\mathrm{t}_{2}-\mathrm{t}_{1}\right) \log \left(\mathrm{V}_{\mathrm{d}} / \mathrm{V}_{1}\right) / \log \left(\mathrm{V}_{2} / \mathrm{V}_{1}\right)
$$

where $t_{d}$ is the interpolated doubling time; $t_{1}$ and $t_{2}$ are the lower and upper observation times bracketing the doubling tumor volume; $\mathrm{V}_{\mathrm{d}}=2 \mathrm{~V}_{0}$, where $\mathrm{V}_{0}$ is the initial tumor volume; and $V_{1}$ and $V_{2}$ are tumor volumes at the times $\mathrm{t}_{1}$ and $\mathrm{t}_{2}$, respectively;

3. The tumor growth delay index, calculated as the mean treated/control tumor growth doubling time ratio.

Animals were euthanized, for ethical reasons, when tumor volume reached $\sim 2000 \mathrm{~mm}^{3}$.

Body weight (BW) was measured on alternate days, and toxicity was evaluated on the basis of net BW reduction. The percentage of net BW variation between the first day of treatment and the day of interest was evaluated according to the following equation:

$\%$ net $\mathrm{BW}$ variation $=\left[\frac{(\text { net } \mathrm{BW} \text { at observation day }- \text { net } \mathrm{BW} \text { at first day of treatment })}{\text { net } \mathrm{BW} \text { at first day of treatment }}\right] \times 100$

The intracranial transplantation procedure was performed as previously described (Tentori et al., 2003). Briefly, cells $\left(10^{6}\right.$ in $0.03 \mathrm{ml}$ of serum-free medium) were injected intracranially through the center middle area of the frontal bone of 5-week-old male CD1 nude mice (weight, 24-26 g; Charles River) to a depth of $2 \mathrm{~mm}$, using a 0.05-ml glass microsyringe and a 27-gauge disposable needle. Before tumor challenge, animals were anesthetized with a ketamine/xylazine solution at doses of 100 and $12.5 \mathrm{mg} / \mathrm{kg}$, respectively (Ketavet $100 \mathrm{mg} / \mathrm{ml}$; MSD Animal Health, Milan, Italy; Rompum, $20 \mathrm{mg} / \mathrm{ml}$; Bayer, Milan, Italy). Treatment with D16F7 (10 or $20 \mathrm{mg} / \mathrm{kg}$ ) was started the day after tumor challenge. BW was measured thrice weekly; survival times were recorded for 60 days, and median survival times were determined. Animals were euthanized, for ethical reasons, when a loss of $>20 \%$ of BW or signs of neurologic deficit were present.

Histologic examination of the brains was performed using additional animals that were not considered for the calculation of survival times. At sacrifice, brains were excised, fixed in $10 \%$ buffered formalin solution (v/v), paraffin embedded and cut into $5 \mu \mathrm{m}$-thick slices for staining. A set of slides was stained with hematoxylin-eosin for morphologic study, mitotic and apoptotic cell counts. Additional slides were stained with anti-mouse PECAM/CD31 goat polyclonal antibody (M-20; Santa Cruz Biotechnology), to label blood vessels. Reactions were revealed with 3,30-diaminobenzidine.

All procedures involving mice and care were conducted in agreement with ethical standards of the Declaration of Helsinki, in compliance with our institutional animal care guidelines, and following national and international directives (D.L. March 4, 2014, no. 26; directive 2010/63/EU of the European parliament and council; Guide for the Care and Use of Laboratory Animals, US National Research Council, 2011). Experimental protocols were approved by the Animal Care and Use Committee at the institutions involved in this study and by the Italian Ministry of Health (project authorization number 619/2015-PR).

\section{Statistical Analyses}

Statistical analysis of the differences between pairs of groups was performed by Student's $t$ test. For multiple comparisons, ANOVA followed by Bonferroni's post-test was used. Survival curves were generated by Kaplan-Meier product-limit estimate, and statistical differences among the various groups were evaluated by log-rank analysis using SPSS software. Statistical significance was determined at the $\alpha=0.05$ level. Differences were considered statistically significant at $P<0.05$. 


\section{Results}

The anti-VEGFR-1 D16F7 mAb Inhibits Migration, ECM Invasion, and Receptor Activation in Response to VEGF-A and PIGF in C6 Cells Transfected with the Human VEGFR-1

We recently demonstrated that the anti-VEGFR-1 D16F7 $\mathrm{mAb}$ inhibits human melanoma and GBM chemotaxis in response to PlGF (Graziani et al., 2016; Atzori et al., 2017). For this study, which aimed at evaluating the in vivo efficacy of D16F7 against glioma, the rat $\mathrm{C} 6$ glioma cell line was chosen since it forms highly angiogenic gliomas when injected in vivo, similar to the same tumors of human origin. Moreover, C6 glioma has been widely used as a reliable model of GBM, also presenting high similarity with human glioma in the gene expression pattern during tumor progression (Grobben et al., 2002). Since the expression of VEGFR-1 protein in C6 cells is undetectable (Plate et al., 1993; Leopol'd et al., 2012), and the weak kinase activity of the receptor renders difficult the study of the influence of D16F7 on VEGFR-1 autophosphorylation and downstream signal transduction, the human VEGFR-1 membrane form was overexpressed in C6 cells. One clone obtained from C6 cells was transfected with control or VEGFR-1 cDNA-containing vectors, and some blasticidine-selected clones were analyzed by RT-PCR and Western blotting for the expression of the human VEGFR-1 (Fig. 1, A and B). For further experiments on the influence of
D16F7 on migration, ECM invasion, and signal transduction, one control clone (i.e., C6-CTR2) and the clone exhibiting the greatest VEGFR-1 protein expression were used (i.e., C6-MF1). Analysis of the chemotactic response of C6-derived clones to PlGF indicated that VEGFR-1-overexpressing cells showed a significantly higher basal migration rate compared with $\mathrm{C} 6$ cells transfected with the control vector and that PlGF further stimulated solely C6-MF1 chemotaxis (Fig. 1C). Interestingly, treatment with $5 \mu \mathrm{g} / \mathrm{ml}$ D16F7 (a concentration capable of hampering melanoma and GBM cell migration; Graziani et al., 2016; Atzori et al., 2017) inhibited PlGF-induced migration of VEGFR-1 overexpressing cells, reverting the chemotactic response to background values (Fig. 1C). On the other hand, a species- and isotype-matched control (IgG1) did not affect PlGFinduced tumor cell migration (Fig. 1D), in accordance with previous studies (Graziani et al., 2016; Atzori et al., 2017). Treatment with D16F7 of C6-MF1 cells reduced not only chemotaxis (Fig. 2, A and B) but also ECM invasion (Fig. 2, C and $\mathrm{D}$ ) in response to both PlGF and VEGF-A.

We then investigated whether receptor stimulation in transfected cells by the VEGFR-1-selective ligand PIGF might cause receptor phosphorylation at Tyr 1213, which is regarded as one of the major autophosphorylation sites responsible for the activation of intracellular signaling pathways (Igarashi et al., 1998, Yu et al., 2001), and whether D16F7 could inhibit this effect.
A

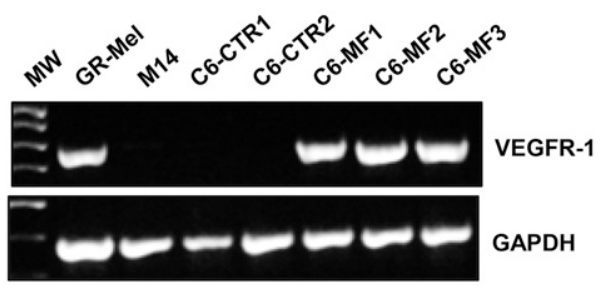

C

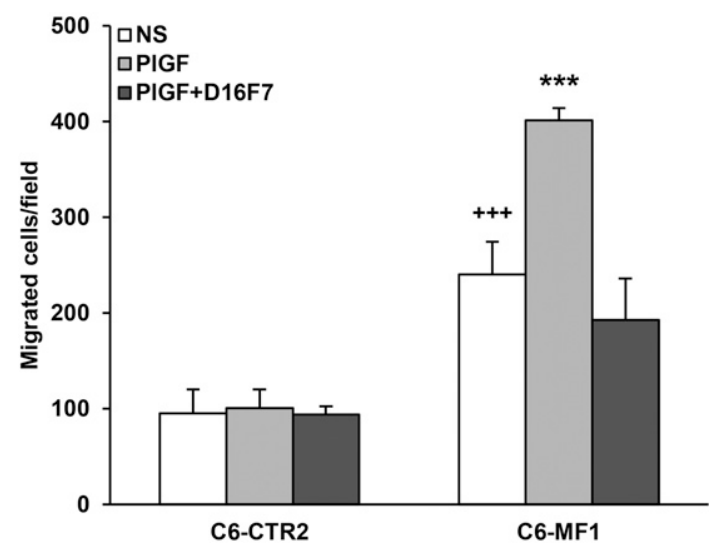

B

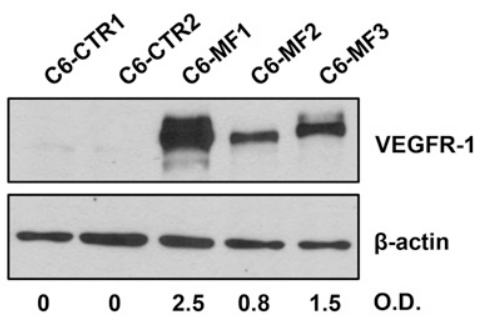

$\mathbf{D}$

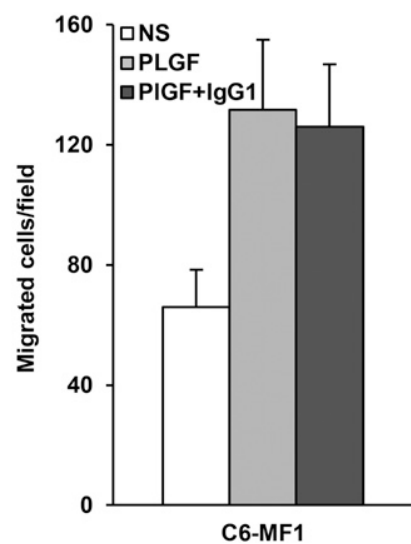

Fig. 1. PlGF-induced migration and D16F7 inhibitory effects on C6 cells transfected with human VEGFR-1. (A) Analysis of human VEGFR-1 transcript levels in transfected C6 clones. VEGFR-1 mRNA levels in C6-derived clones transfected with control (C6-CTR1, C6-CTR2) or VEGFR-1-expressing (C6MF1, C6-MF2, C6-MF3) vectors were analyzed by RT-PCR. Amplified products were separated on 1\% agarose gels, and results are representative of one out of two independent experiments. The human melanoma GR-Mel and M14 cell lines were used as positive and negative controls, respectively. MW, molecular weight markers. (B) Analysis of human VEGFR-1 protein in transfected C6 clones. VEGFR-1 protein levels in C6-derived clones transfected with control or VEGFR-1-expressing vectors were analyzed by Western blotting. (C) Cell migration of transfected C6 cells in response to PlGF. Migration of C6-CTR2 and C6-MF1 cells in response to serum-free medium or PlGF $(50 \mathrm{ng} / \mathrm{ml})$ was analyzed after 18 hours of incubation, in the absence or presence of $5 \mu \mathrm{g} / \mathrm{ml} \mathrm{D} 16 \mathrm{~F} 7$. Results of statistical analysis using one-way ANOVA, followed by Bonferroni's post-test were as follows: comparisons between PIGF C6-MF1 and all the other groups, ${ }^{* * *} P<0.001$; comparisons between NS C6-MF1 and C6-CTR2 groups, ${ }^{+++} P<0.001$. (D) Influence of an isotype-matched control Ab (IgG1) on the chemotactic response of C6-MF1 cells to PlGF. Cell migration in response to PlGF (50 ng/ml) was analyzed after 6 hours of incubation, in the absence or presence of $5 \mu \mathrm{g} / \mathrm{ml}$ control IgG1. NS, nonstimulated cells. Differences between PlGF and PlGF+IgG1 were not significant. 
Exposure of C6-MF1 cells to PlGF for 10 minutes markedly increased VEGFR-1 protein phosphorylation and pretreatment with D16F7 reduced receptor tyrosine kinase activity (Fig. 3A). Similarly, VEGF-A induced VEGFR-1 phosphorylation at Tyr 1213 and also in this case D16F7 substantially reduced VEGFR-1 phosphorylation triggered by this angiogenic factor (Fig. 3B). Comparable results were obtained in another VEGFR-1-transfected clone (i.e., C6-MF3) (Supplemental Fig. 1).

Since VEGFR-1 activation by VEGF-A or PlGF stimulates Erk1/2 of the MAPK signaling pathway, promoting tumor cell invasion and migration (Koch et al., 2011; Atzori et al., 2017), we investigated whether VEGF-A-induced or PlGF-induced receptor autophosphorylation at Tyr 1213 in C6-MF1 cells was followed by Erk1/2 phosphorylation and whether D16F7 could prevent Erk1/2 activation. Notably, D16F7 markedly inhibited Erk1/2 phosphorylation stimulated by both ligands (Fig. 3, A and E). Quantitative results are reported as the percentage inhibition of VEGFR-1 and Erk1/2 phosphorylation by D16F7 (Fig. 3C).

\section{D16F7 Inhibits GBM Growth and Angiogenesis In Vivo}

We recently demonstrated that 10 or $20 \mathrm{mg} / \mathrm{kg}$ D16F7 intraperitoneal treatment is well tolerated and exerts antitumor activity in a melanoma syngeneic mouse model (Graziani et al., 2016). The in vivo antitumor activity of D16F7 against C6-MF1 was tested in immunodeficient mice, since spontaneous tumor regression has been described when $\mathrm{C} 6$ cells were injected into syngeneic rats (Vince et al., 2004). D16F7 mAb recognizes both human and murine VEGFR-1, likely due to a difference of two amino acids only between the peptide used as immunogen and the corresponding region of murine VEGFR1. Indeed, enzyme-linked immunosorbent assay using the human and murine VEGFR-1 extracellular domain showed that D16F7 specifically binds not only the human type 1 receptor, as previously reported (Graziani et al., 2016), but also the murine protein with similar affinity (Supplemental Fig. 2). Thus, D16F7 allows the analysis of the effect of mAb on the tumor graft and host tumor microenvironment as well.

The effect of D16F7 on glioma growth was initially evaluated by injecting C6-MF1 cells intramuscularly in athymic nude mice and, when tumors were palpable, treating them with $20 \mathrm{mg} / \mathrm{kg}$ D16F7 intraperitoneally on alternate days for 2 weeks. Treatment with D16F7 did not cause toxic effects. In fact, compared with control animals treated with mAb solvent, no significant changes in $\mathrm{BW}$ were observed in mice treated with D16F7 (Fig. 4A). Substantial reduction in tumor volume was observed in D16F7-treated animals (Fig. 4B). In fact, D16F7 treatment resulted in $50 \%$ inhibition of tumor growth on day 12 after tumor challenge, significantly increased tumor growth doubling time (CTR, 5.1 days \pm 0.9 vs. D16F7, 10.8 days \pm 0.5 ; $P<0.0001$ ], and imposed a tumor growth delay index of $2.11 \pm$ 0.08 .

We next injected C6-MF1 cells intracranially, and, on day 1 after tumor challenge, mice were treated with 10 or $20 \mathrm{mg} / \mathrm{kg}$ D16F7 intraperitoneally on alternate days for 4 weeks. Survival analysis revealed that D16F7 treatment increased life span by $40 \%$ and $65 \%$ at doses of 10 and $20 \mathrm{mg} / \mathrm{kg}$, respectively (Fig. 5A). In fact, the median survival time of control animals was 20 days (range, 18-28 days), whereas the median survival times of D16F7-treated animals were 28 days (range, 22-36 days) and 33 days (22 to $>60$ days) for 10 and
$20 \mathrm{mg} / \mathrm{kg}$ treatments, respectively. Strikingly, in the group treated with $20 \mathrm{mg} / \mathrm{kg} \mathrm{D16F7,} \mathrm{we} \mathrm{observed} 46 \%$ of long-term survivors during 8 weeks of observation despite discontinuing treatment after the fourth week. Brain histology of long-term survivors revealed the presence of a limited number of glioma cells, supporting the strong inhibitory effect of D16F7 on tumor growth (Supplemental Fig. 3).

Three mice from control and D16F7-treated groups $(20 \mathrm{mg} / \mathrm{kg})$ were sacrificed for histologic analysis 3 weeks after tumor challenge (i.e., a time corresponding to the median survival time of control mice). Hematoxylin-eosin staining and immunohistochemical analysis of brain sections obtained from control mice exhibited a wide neoplastic mass with infiltrative growth pattern and high mitotic rate, containing highly vascularized areas as indicated by large capillaries positively stained by anti-CD31 antibody (Fig. 5, B and C). A highmagnification image shows healthy cells with several mitotic figures (Fig. 5B, 60×).

Conversely, brain tissues from D16F7-treated mice exhibited limited tumor formation with some strands of tumor cells and fewer vessels that were reduced in size (Fig. 5, B and C). Neoplastic cells showed a regressive aspect characterized by shrunken nuclei, condensed chromatin, pycnosis, and apoptotic pictures (Fig. 5B). Indeed, compared with control samples, sections from D16F7-treated animals revealed reduced mitotic activity and increased apoptotic cell number (Fig. 5B).

\section{Discussion}

In the present study, we demonstrate for the first time that a novel anti-VEGFR-1 mAb (D16F7), which in vitro diminishes receptor activation by its ligands VEGF-A and PlGF, as a single agent decreases glioma growth and angiogenesis in vivo in an orthotopic xenograft model.

VEGFR-1 is expressed in endothelial cells of tumorassociated vessels, but it is absent from endothelial cells in the normal brain (Plate et al., 1993), which restricts the action of VEGF and PlGF to tumor endothelium. Moreover, studies performed in a cohort of high-grade glioma patients have shown that VEGFR-1 is also expressed in tumor cells (Atzori et al., 2017) and at significantly higher levels compared with lower-grade gliomas (Baumgarten et al., 2016). VEGFR-1 can transmit signals that promote GBM cell invasion and, since both VEGFR-1 and its ligands are frequently expressed by GBM cells, D16F7 is expected to interrupt an autocrine loop that favors tumor aggressiveness. Indeed, besides VEGF-A, the selective VEGFR-1 ligand PlGF also has been found to be expressed in high-grade gliomas where it stimulates angiogenesis either directly or by enhancing VEGF-driven angiogenesis (Fischer et al., 2008). Since D16F7 interacts with VEGFR-1 expressed by endothelial cells lining tumor-associated vessels and with the receptor present in glioma cells, the expected benefit of D16F7 treatment may derive from inhibition of the tumorinfiltrative behavior and angiogenesis.

The C6 glioma resembles histopathological key features of human GBM, as follows: 1) presence of necrotic areas throughout the tumors; 2) palisading cells lined up at the periphery of necrotic areas; and 3) numerous blood vessels within the tumor (Plate et al., 1993). C6 intramuscular xenografts in nude mice have been used as a model of highly proliferative and angiogenic tumors to test the influence 
A

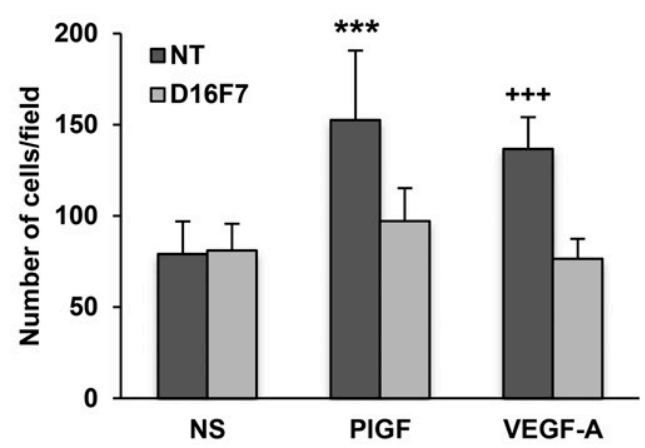

B

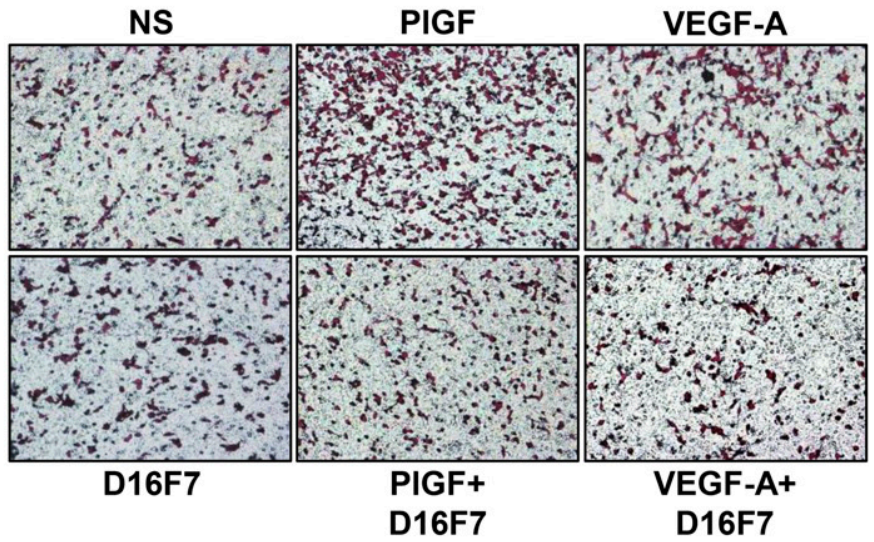

C

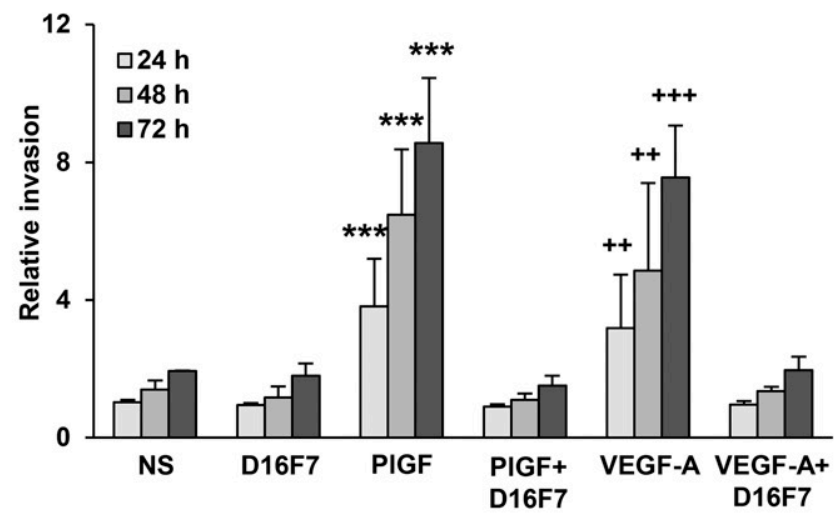

D

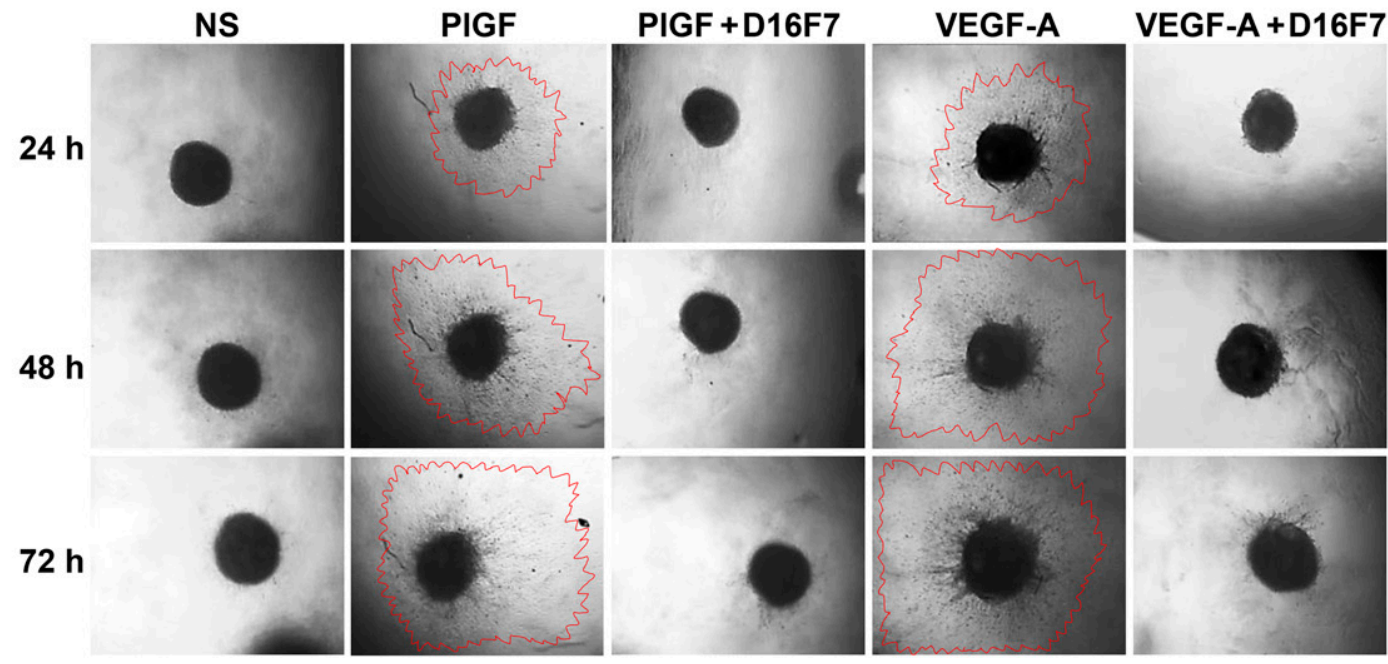

Fig. 2. D16F7 inhibits VEGF-A or PlGF-induced chemotaxis and ECM invasion of C6 cells overexpressing VEGFR-1. (A) Migration of C6-MF1 cells in response to PlGF or VEGF-A was analyzed after 6 hours of incubation, in the absence (NT, not treated) or presence of $5 \mu \mathrm{g} / \mathrm{ml} \mathrm{D} 16 \mathrm{~F} 7$. NS, nonstimulated cells. Histogram represents the mean \pm S.D. $(n=3)$ of migrated cells/microscopic field. The results of statistical analysis using one-way ANOVA, followed by Bonferroni's post-test were as follows: PlGF vs. NS, PlGF vs. D16F7, or PlGF vs. PlGF+D16F7, *** $P<0.001$; VEGF-A vs. NS, VEGF-A vs. D16F7, or VEGF-A vs. VEGF-A+D16F7, ${ }^{+++} P<0.001$; differences between NS, D16F7, PlGF+D16F7, and VEGF-A+D16F7 were not significant. (B) Photographs from a representative migration experiment with C6-MF1 cells in response to PlGF or VEGF-A. Original magnification, 100×. (C) For spheroid invasion assay, C6-MF1 cells were embedded in collagen I in the absence or presence of D16F7 (10 $\mu \mathrm{g} / \mathrm{ml})$ and PlGF or VEGF-A (50 ng/ml). Relative invasion was quantified as the spheroid area difference (in square millimeters) at each of the indicated time points minus day 0. Data are expressed as the mean \pm S.D. of relative invasion $(n=5-8)$. NS, nonstimulated cells. The results of statistical analysis were as follows: PlGF vs. NS and PlGF vs. PlGF+D16F7 at 24,48 , and 72 hours, $* * * P<0.001$; VEGF-A vs. NS and VEGF-A vs. VEGF-A+D16F7 at 24 and 48 hours, ${ }^{++} P<0.01$; at 72 hours, ${ }^{++} P<0.001$. Differences between NS and PIGF +D16F7 or NS and VEGF-A+D16F7 were not significant. (D) Representative pictures of spheroids taken at 24, 48, and 72 hours. Original magnification, 40×. 
A

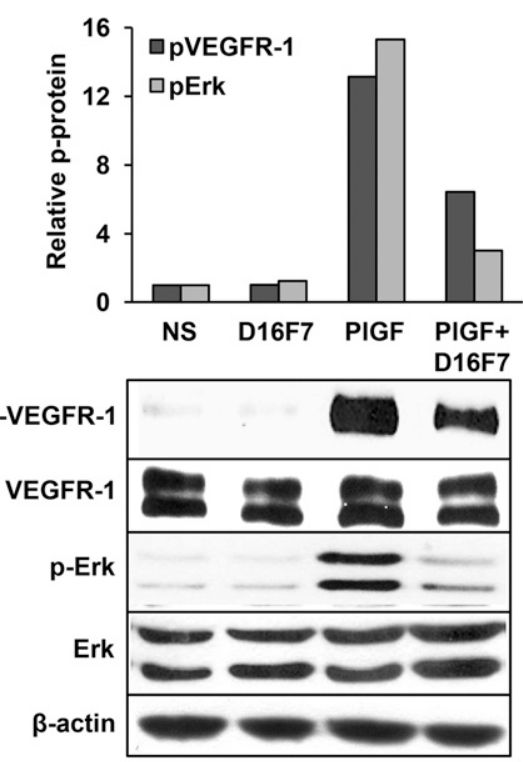

B
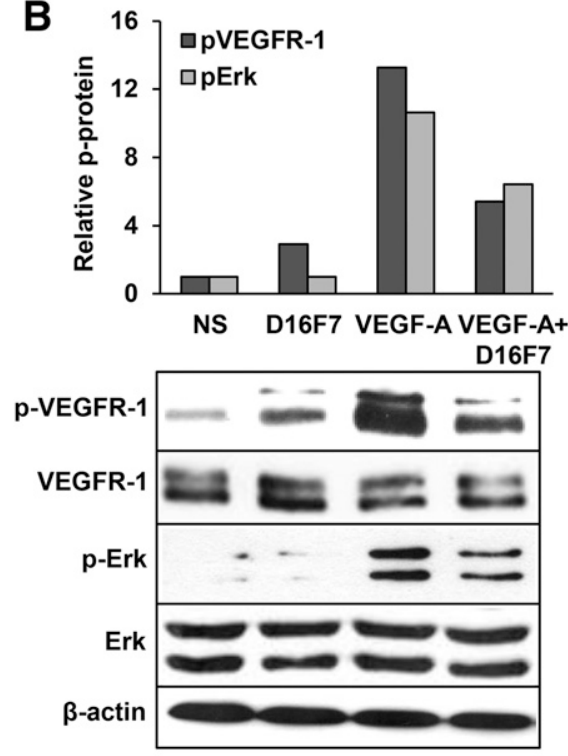

Fig. 3. Inhibition by D16F7 of VEGF-A- and PlGF-induced phosphorylation of VEGFR-1 and Erk1/2 in C6 cells overexpressing VEGFR-1. Western blotting of total or phosphorylated VEGFR-1 (pVEGFR-1) at tyrosine 1213 and total or phosphorylated Erk1/2 (pErk) in untreated or D16F7 $(10 \mu \mathrm{g} / \mathrm{ml})$ pretreated C6-MF1 cells in response to $100 \mathrm{ng} / \mathrm{ml}$ PlGF (A) or VEGF-A (B). Histograms represent the densitometric quantification of band intensities in the corresponding immunoblots, expressed as the pVEGFR-1/VEGFR-1 ratio relative to an untreated control, after normalization for $\beta$-actin expression. The normalized pVEGFR-1/VEGFR-1 ratio in untreated cells was considered equal to 1. (C) Histogram represents the mean \pm S.D. $(n=3)$ percentage inhibition values of PlGF- or VEGF-Ainduced VEGFR-1 or Erk1/2 phosphorylation in C6-MF1 cells after treatment with $10 \mu \mathrm{g} / \mathrm{ml}$ D16F7, calculated from immunoblot densitometric analysis.
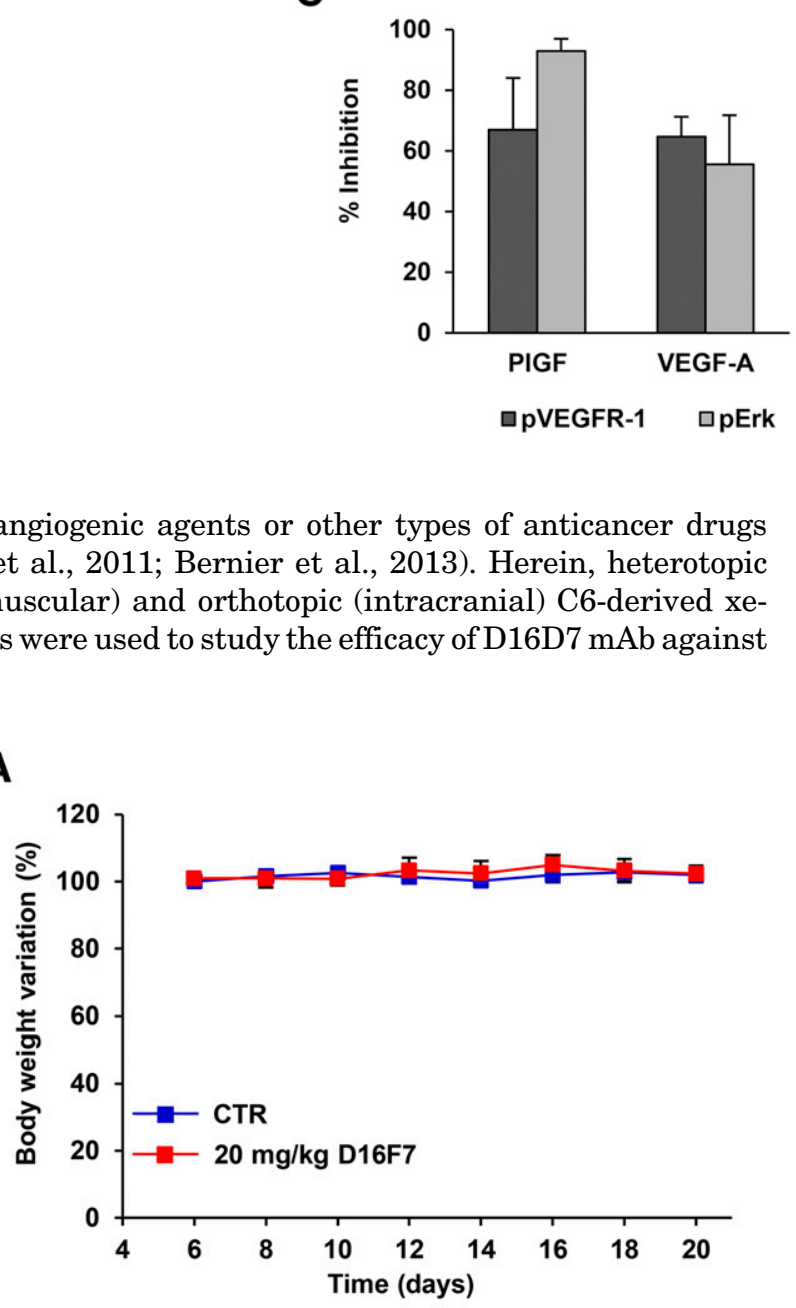

B

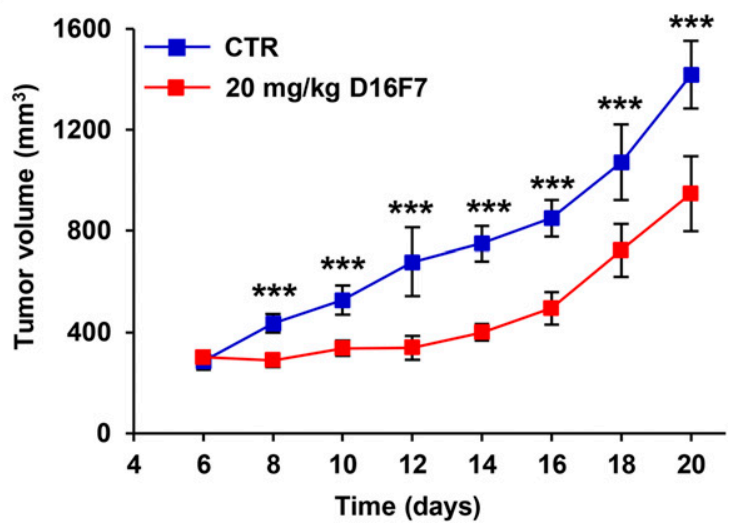

Fig. 4. D16F7 treatment inhibits in vivo growth of C6-MF1 cells injected intramuscularly. (A) Safety analysis of D16F7 treatment. Toxicity of D16F7 $\mathrm{mAb}$ treatment was evaluated on the basis of net BW reduction in nude mice treated for 2 weeks with vehicle $(\mathrm{CTR})$ or $20 \mathrm{mg} / \mathrm{kg}$ D16F7 on alternate days (eight animals/group). Data represent the BW variation with respect to the first day of treatment, to which the arbitrary value of 100 was assigned. (B) Antitumor activity of D16F7 against intramuscular xenograft. C6-MF1 cells were injected intramuscularly in the left hind limb of nude mice and, 6 days after tumor challenge, animals were treated with vehicle (CTR) or with D16F7 mAb $(20 \mathrm{mg} / \mathrm{kg})$. Results are the mean \pm S.D. $(n=8)$ of tumor volumes. Data are representative of two independent experiments with similar results. Student's $t$ test analysis, ${ }^{* * *} P<0.001$. 


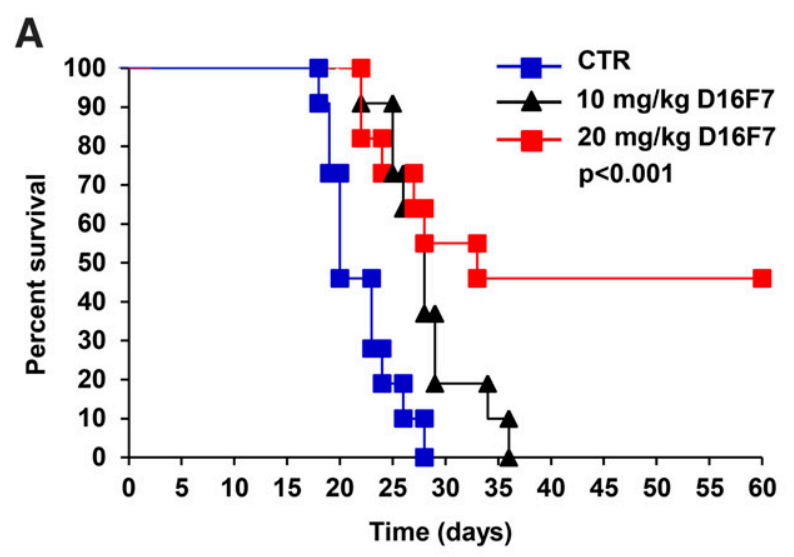

B
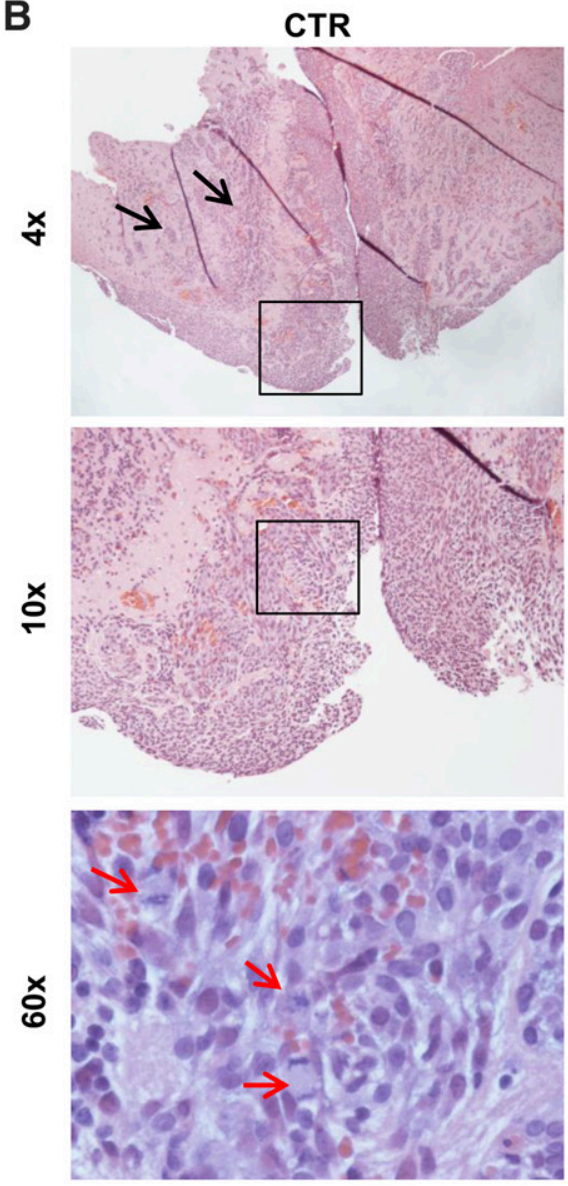

C

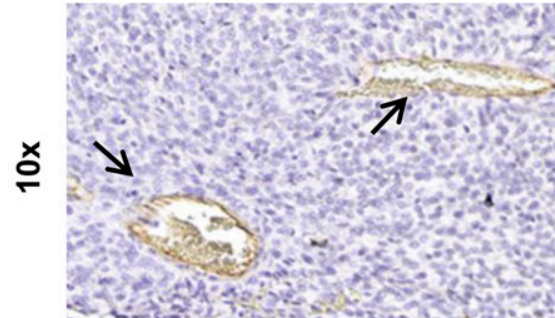

CTR

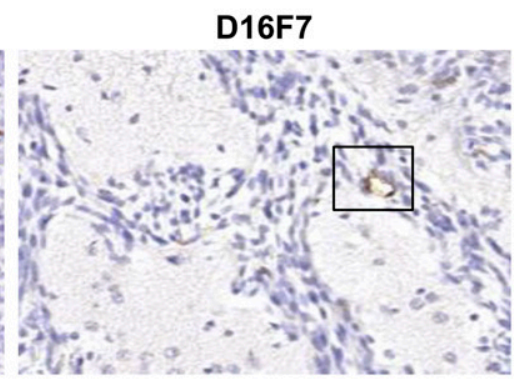

D16F7

whishon. ist
D16F7
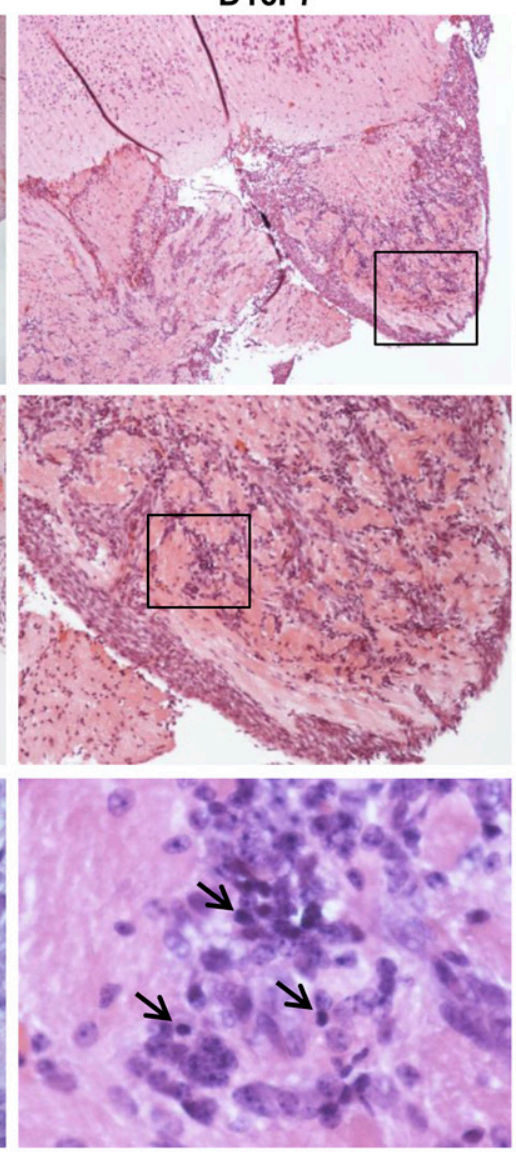
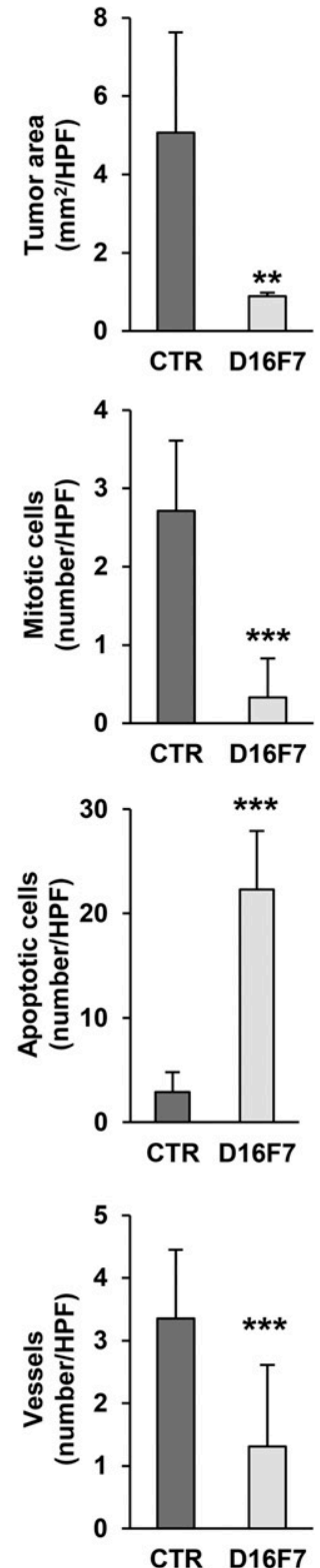

Fig. 5. D16F7 treatment prolongs the survival of animals orthotopically injected with C6-MF1 glioma cells. (A) C6-MF1 cells were injected intracranially into nude mice $(n=11)$. Survival curves were generated by a Kaplan-Meier product-limit estimate, and statistical differences between the various groups were evaluated by log-rank analysis: CTR vs. 10 or $20 \mathrm{mg} / \mathrm{kg}$ D16F7, $P<0.001$. (B) H\&E staining of brain histologic sections from CTR mice and $20 \mathrm{mg} / \mathrm{kg}$ D16F7 mAb-treated mice. Histograms represent the mean \pm S.D. area of the tumor occupied by cancer cells (original magnification, $4 \times$ ) or the number of mitotic and apoptotic (original magnification, $40 \times$ ) tumor cells/high-power fields $(n=20)$. Red arrows in the CTR 
A

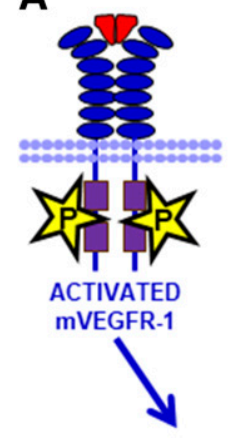

Erk Akt PI3K p38

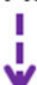

Migration

Invasion

Proliferation

Survival
B

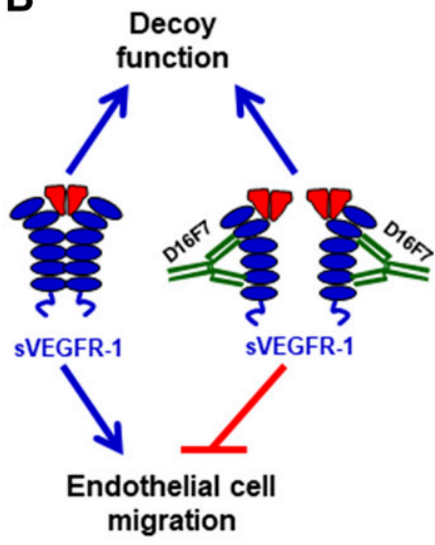

Fig. 6. Mechanism of action of the anti-VEGFR-1 D16F7 $\mathrm{mAb}$. The anti-VEGFR-1 D16F7 mAb interacts with a receptor site corresponding to amino acids 149-161 of human VEGFR-1 (Graziani et al., 2016), which is different from that involved in VEGF-A or PIGF binding (DavisSmyth et al., 1998; Christinger et al., 2004). Thus, the D16F7 $\mathrm{mAb}$ does not prevent ligand interaction with the transmembrane or soluble receptor. (A) The mAb hampers receptor homodimerization and signal transduction with consequent inhibition of tumor and microenvironment cell functions. (B) D16F7 mAb preserves the soluble VEGFR-1 (sVEGFR-1) the ability to sequester receptor ligands (decoy function) and inhibits endothelial cell migration in response to sVEGFR-1. Akt, protein kinase B; Erk, extracellular signal-regulated kinase; PI3K, phosphatidylinositol 3-kinase. a higher migration rate compared with control cells, and their chemotactic activity was markedly stimulated by exogenous PlGF and VEGF-A. Since C6 cells are known to secrete PlGF (Heidenreich et al., 2004), these finding suggest the possibility that a PlGF/VEGFR-1 autocrine loop might promote tumor migration. In fact, exposure to the anti-VEGFR-1 D16F7 mAb reverted the migratory and invasive behavior of VEGFR1-proficient glioma cells.

Treatment of nude mice with D16F7 on alternate days was well tolerated and resulted in substantially reduced tumor growth in the heterotopic intramuscular model. Interestingly, results demonstrated that systemically administered D16F7 was also effective against glioma cells growing at the central nervous system site. The antitumor activity was associated with reduced vessel formation, induction of apoptosis, and decreased proliferative potential in glioma cells. The antiangiogenic effects exerted by D16F7 in the murine model is due to the mAb ability of also recognizing the mouse VEGFR-1. Indeed, we found that D16F7 was able to bind in vitro the extracellular domain of the purified murine and human VEGFR-1 protein with similar affinity. Therefore, this property of D16F7 allows the observation of the influence of VEGFR-1 blockade not only on glioma cells but also on the tumor microenvironment.

The inhibitory activity exerted by D16F7 on glioma growth translated in a dose-dependent and statistically significant increase of tumor-bearing mice survival time. Interestingly, treatment with $20 \mathrm{mg} / \mathrm{kg}$ D16F7 led to a high percentage of long-term survivors. These data are in agreement with VEGFR-1 involvement in GBM cell viability in vivo, as demonstrated by the survival benefit observed upon injection of VEGFR-1-silenced cancer cells into nude mice (Szabo et al., 2016).

The antibodies anti-VEGFR-1 generated so far have been designed to inhibit receptor activity by preventing the interaction with its ligands (Wu et al., 2006). Conversely, D16F7 has an innovative mechanism of action since it does not affect the ligand binding to the transmembrane tyrosine kinase receptor, whereas it inhibits receptor autophosphorylation and signal transduction (Fig. 6). Consequently, D16F7 leaves intact the ability of the soluble VEGFR-1 to sequester VEGF-A and PlGF. This is particularly important considering the previously suggested role of the soluble receptor in controlling tumor progression. In fact, in GBM the low-soluble VEGFR-1/VEGF-A ratio has been related to higher aggressiveness compared with astrocytomas (Lamszus et al., 2003). In addition, soluble VEGFR-1 exerts chemotactic effects on endothelial cells (Fig. 6), indicating a role for this receptor isoform in angiogenesis (Orecchia et al., 2003; Graziani et al., 2016). Interestingly, D16F7 was found to impair endothelial cell migration in response to soluble VEGFR-1 (Fig. 6), counteracting its paradoxical proangiogenic effect (Graziani et al., 2016). Moreover, since VEGF-A has a higher affinity for VEGFR-1 than VEGFR-2 (Shibuya, 2011), a molecule like D16F7 that does not compete with VEGF-A for the binding to the receptor is expected to exert antitumor/ antiangiogenic effects at lower concentrations compared to mAbs that inhibit the interaction of the ligands with VEGFR1 in a competitive way.

The favorable tolerability profile of D16F7 may be explained with the lack of VEGFR-1 involvement in physiologic angiogenesis, and it is predictable that this $\mathrm{mAb}$ will improve the clinical response to therapies directed toward VEGF-A/VEGFR-2 or to chemotherapeutic and targeted agents without additive toxicity.

In conclusion, the results presented indicate that VEGFR-1 is an appropriate target for reducing glioma aggressiveness promoted by VEGF-A and PlGF, and that D16F7-derived humanized mAbs warrant further investigation for therapeutic intervention of high-grade glioma.

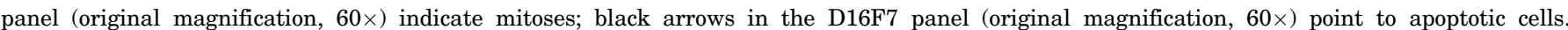

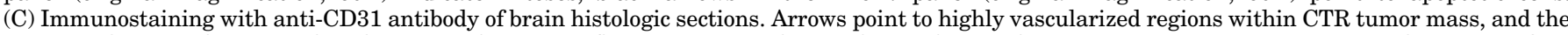

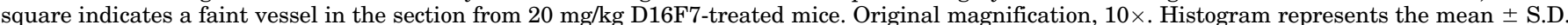
number of vessels/high-power field $(n=20)$. Student's $t$ test analysis: $* * P<0.01 ; * * * P<0.001$. 


\section{Authorship Contributions}

Participated in research design: Lacal and Graziani.

Conducted experiments: Atzori, Tentori, Ruffini, Ceci, and Scimeca. Performed data analysis: Tentori, Bonanno, Lacal, and Graziani.

Wrote or contributed to the writing of the manuscript: Lacal and Graziani.

\section{References}

Atzori MG, Tentori L, Ruffini F, Ceci C, Lisi L, Bonanno E, Scimeca M, Eskilsson E, Daubon T, Miletic H, et al. (2017) The anti-vascular endothelial growth factor receptor-1 monoclonal antibody D16F7 inhibits invasiveness of human glioblastoma and glioblastoma stem cells. J Exp Clin Cancer Res 36:106.

Baumgarten P, Blank AE, Franz K, Hattingen E, Dunst M, Zeiner P, Hoffmann K Bähr O, Mäder L, Goeppert B, et al. (2016) Differential expression of vascular endothelial growth factor A, its receptors VEGFR-1, -2 , and -3 and co-receptors neuropilin-1 and -2 does not predict bevacizumab response in human astrocytomas. Neuro-oncol 18:173-183.

Bernier M, Paul RK, Dossou KS, Wnorowski A, Ramamoorthy A, Paris A, Moaddel R, Cloix JF, and Wainer IW (2013) Antitumor activity of (R, $\left.\mathrm{R}^{\prime}\right)$-4-methoxy-1 naphthylfenoterol in a rat $\mathrm{C} 6$ glioma xenograft model in the mouse. Pharmacol Res Perspect 1:e0010.

Cao Y (2009) Positive and negative modulation of angiogenesis by VEGFR1 ligands. Sci Signal 2:re1.

Christinger HW, Fuh G, de Vos AM, and Wiesmann C (2004) The crystal structure of placental growth factor in complex with domain 2 of vascular endothelial growth factor receptor-1. J Biol Chem 279:10382-10388.

Davis-Smyth T, Presta LG, and Ferrara N (1998) Mapping the charged residues in the second immunoglobulin-like domain of the vascular endothelial growth factor/ placenta growth factor receptor Flt-1 required for binding and structural stability. $J$ Biol Chem 273:3216-3222.

Dewerchin M and Carmeliet P (2014) Placental growth factor in cancer. Expert Opin Ther Targets 18:1339-1354.

Diaz RJ, Ali S, Qadir MG, De La Fuente MI, Ivan ME, and Komotar RJ (2017) The role of bevacizumab in the treatment of glioblastoma. $J$ Neurooncol 133:455-467.

Eskilsson E, Rosland GV, Talasila KM, Knappskog S, Keunen O, Sottoriva A, Foerster S, Solecki G, Taxt T, Jirik R, et al. (2016) EGFRvIII mutations can emerge as late and heterogenous events in glioblastoma development and promote angiogenesis through Src activation. Neuro Oncol 18:1644-1655.

Ferrara N, Gerber HP, and LeCouter J (2003) The biology of VEGF and its receptors. Nat Med 9:669-676.

Fischer C, Mazzone M, Jonckx B, and Carmeliet P (2008) FLT1 and its ligands VEGFB and PlGF: drug targets for anti-angiogenic therapy? Nat Rev Cancer 8:942-956.

Graziani G, Ruffini F, Tentori L, Scimeca M, Dorio AS, Atzori MG, Failla CM, Morea V, Bonanno E, D'Atri S, et al. (2016) Antitumor activity of a novel anti-vascular endothelial growth factor receptor-1 monoclonal antibody that does not interfere with ligand binding. Oncotarget 7:72868-72885.

Grobben B, De Deyn PP, and Slegers H (2002) Rat C6 glioma as experimental model system for the study of glioblastoma growth and invasion. Cell Tissue Res $\mathbf{3 1 0}$ $257-270$.

Heidenreich R, Machein M, Nicolaus A, Hilbig A, Wild C, Clauss M, Plate KH, and Breier G (2004) Inhibition of solid tumor growth by gene transfer of VEGF receptor-1 mutants. Int $J$ Cancer 111:348-357.

Higa GM and Abraham J (2009) Biological mechanisms of bevacizumab-associated adverse events. Expert Rev Anticancer Ther 9:999-1007.

Hundsberger T, Reardon DA, and Wen PY (2017) Angiogenesis inhibitors in tackling recurrent glioblastoma. Expert Rev Anticancer Ther 17:507-515.

Igarashi K, Isohara T, Kato T, Shigeta K, Yamano T, and Uno I (1998) Tyrosine 1213 of Flt-1 is a major binding site of Nck and SHP-2. Biochem Biophys Res Commun 246:95-99.

Kim KJ, Cho CS, and Kim WU (2012) Role of placenta growth factor in cancer and inflammation. Exp Mol Med 44:10-19.

Koch S, Tugues S, Li X, Gualandi L, and Claesson-Welsh L (2011) Signal transduction by vascular endothelial growth factor receptors. Biochem $J$ 437:169-183.

Lacal PM, Morea V, Ruffini F, Orecchia A, Dorio AS, Failla CM, Soro S, Tentori L, Zambruno G, Graziani G, et al. (2008) Inhibition of endothelial cell migration and angiogenesis by a vascular endothelial growth factor receptor-1 derived peptide. Eur J Cancer 44:1914-1921.

Lamszus K, Ulbricht U, Matschke J, Brockmann MA, Fillbrandt R, and Westphal M (2003) Levels of soluble vascular endothelial growth factor (VEGF) receptor 1 in astrocytic tumors and its relation to malignancy, vascularity, and VEGF-A. Clin Cancer Res 9:1399-1405.

Leopol'd AV, Baklaushev VP, Korchagina AA, Shein SA, Grinenko NF, Pavlov KA, Ryabukhin IA, and Chekhonin VP (2012) Ligand-receptor assay for evaluation of functional activity of human recombinant VEGF and VEGFR-1 extracellular fragment. Bull Exp Biol Med 152:707-711.
Li C, Liu B, Dai Z, and Tao Y (2011) Knockdown of VEGF receptor-1 (VEGFR-1) impairs macrophage infiltration, angiogenesis and growth of clear cell renal cell carcinoma (CRCC). Cancer Biol Ther 12:872-880.

Luttun A, Tjwa M, and Carmeliet P (2002) Placental growth factor (PlGF) and its receptor Flt-1 (VEGFR-1): novel therapeutic targets for angiogenic disorders. Ann N Y Acad Sci 979:80-93.

Orecchia A, Lacal PM, Schietroma C, Morea V, Zambruno G, and Failla CM (2003) Vascular endothelial growth factor receptor-1 is deposited in the extracellular matrix by endothelial cells and is a ligand for the alpha 5 beta 1 integrin. J Cell Sci 116:3479-3489.

Plate KH, Breier G, Millauer B, Ullrich A, and Risau W (1993) Up-regulation of vascular endothelial growth factor and its cognate receptors in a rat glioma model of tumor angiogenesis. Cancer Res 53:5822-5827.

Qian BZ, Zhang H, Li J, He T, Yeo EJ, Soong DY, Carragher NO, Munro A, Chang A, Bresnick AR, et al. (2015) FLT1 signaling in metastasis-associated macrophages activates an inflammatory signature that promotes breast cancer metastasis. $J$ Exp Med 212:1433-1448.

Roskoski R, Jr (2008) VEGF receptor protein-tyrosine kinases: structure and regulation. Biochem Biophys Res Commun 375:287-291.

Schwartz JD, Rowinsky EK, Youssoufian H, Pytowski B, and Wu Y (2010) Vascular endothelial growth factor receptor-1 in human cancer: concise review and rationale for development of IMC-18F1 (human antibody targeting vascular endothelial growth factor receptor-1). Cancer 116 (4 Suppl):1027-1032.

Shibuya M (2006) Vascular endothelial growth factor receptor-1 (VEGFR-1/Flt-1): a dual regulator for angiogenesis. Angiogenesis 9:225-230.

Shibuya M (2011) Vascular endothelial growth factor (VEGF) and its receptor (VEGFR) signaling in angiogenesis: a crucial target for anti- and pro-angiogenic therapies. Genes Cancer 2:1097-1105.

Steiner HH, Karcher S, Mueller MM, Nalbantis E, Kunze S, and Herold-Mende C (2004) Autocrine pathways of the vascular endothelial growth factor (VEGF) in glioblastoma multiforme: clinical relevance of radiation-induced increase of VEGF levels. J Neurooncol 66:129-138.

Stupp R, Mason WP, van den Bent MJ, Weller M, Fisher B, Taphoorn MJ, Belanger K, Brandes AA, Marosi C, Bogdahn U, et al.; European Organisation for Research and Treatment of Cancer Brain Tumor and Radiotherapy Groups; National Cancer Institute of Canada Clinical Trials Group (2005) Radiotherapy plus concomitant and adjuvant temozolomide for glioblastoma. $N$ Engl Med 352:987-996.

Szabo E, Schneider H, Seystahl K, Rushing EJ, Herting F, Weidner KM, and Weller M (2016) Autocrine VEGFR1 and VEGFR2 signaling promotes survival in human glioblastoma models in vitro and in vivo. Neuro-oncol 18:1242-1252.

Takahashi S (2011) Vascular endothelial growth factor (VEGF), VEGF receptors and their inhibitors for antiangiogenic tumor therapy. Biol Pharm Bull 34: 1785-1788.

Tentori L, Leonetti C, Scarsella M, D'Amati G, Vergati M, Portarena I, Xu W, Kalish V, Zupi G, Zhang J, et al. (2003) Systemic administration of GPI 15427, a novel poly(ADP-ribose) polymerase-1 inhibitor, increases the antitumor activity of temozolomide against intracranial melanoma, glioma, lymphoma. Clin Cancer Res 9:5370-5379.

Tentori L, Vergati M, Muzi A, Levati L, Ruffini F, Forini O, Vernole P, Lacal PM, and Graziani G (2005) Generation of an immortalized human endothelial cell line as a model of neovascular proliferating endothelial cells to assess chemosensitivity to anticancer drugs. Int $J$ Oncol 27:525-535.

Tipping M, Eickhoff J, and Ian Robins H (2017) Clinical outcomes in recurrent glioblastoma with bevacizumab therapy: an analysis of the literature. J Clin Neurosci 44:101-106.

Vince GH, Bendszus M, Schweitzer T, Goldbrunner RH, Hildebrandt S, Tilgner J, Klein R, Solymosi L, Christian Tonn J, and Roosen K (2004) Spontaneous regression of experimental gliomas-an immunohistochemical and MRI study of the C6 glioma spheroid implantation model. Exp Neurol 190:478-485.

Wu Y, Zhong Z, Huber J, Bassi R, Finnerty B, Corcoran E, Li H, Navarro E, Balderes P, Jimenez X, et al. (2006) Anti-vascular endothelial growth factor receptor-1 antagonist antibody as a therapeutic agent for cancer. Clin Cancer Res 12:6573-6584.

Yang L, Lin Z, Lin J, Weng S, Huang Q, Zhang P, and Fu J (2011) Antitumor effect of endostatin overexpressed in $\mathrm{C} 6$ glioma cells is associated with the down-regulation of VEGF. Int $J$ Oncol 38:465-471.

Yu Y, Hulmes JD, Herley MT, Whitney RG, Crabb JW, and Sato JD (2001) Direct identification of a major autophosphorylation site on vascular endothelial growth factor receptor Flt-1 that mediates phosphatidylinositol 3 '-kinase binding. Biochem $J$ 358:465-472.

Address correspondence to: Grazia Graziani, Department of Systems Medicine, University of Rome Tor Vergata, Via Montpellier 1, 00133 Rome, Italy. E-mail: graziani@uniroma2.it; or Pedro Miguel Lacal, Laboratory of Molecular Oncology, "Istituto Dermopatico dell'Immacolata"-IRCCS, Via dei Monti di Creta, 104, 00167 Rome, Italy. E-mail: p.lacal@idi.it 